\title{
Derecho Romano
}

\section{Apuntes sobre el origen de la distinción entre los derechos reales y los derechos de obligaciones}

\author{
Por el Dr. JOSE DAMMERT BELLIDO \\ Catedrático de Derecho Romano de la Universidad Católica.
}

Se ha insistido mucho en que una de las conquistas perdurables debidas a la ciencia jurídica de los romanos es la distinción entre los derechos reales $y$ los derechos de obligaciones en el campo de los derechos patrimoniales. (Ver: Jors-Kunkel, Derecho Privado Romano \& 35, Ne 2).

A este propósito se recuerda la tripartición del Derecho que figura en las Instituciones del jurisconsulto Gayo (II siglo d. Cr.), en la cual se clasifican los derechos que pertenecen a las personas, a las cosas y a las acciones, esto es derechos personales, patrimoniales y procesal. Dicha clasificación figura también en las Instituciones del Emperador Justiniano (VI siglo d. $\mathrm{Cr}$.) y es reproducida en los modernos códigos civiles y adoptada por los tratadistas con fines didácticos.

Aunque en esta tripartición no aparece la antítesis entre los derechos reales y los derechos de obligaciones, sin embargo a lo largo del comentario gayano se percibe nítidamente tal distinción.

Mas los elogios hechos a los jurisconsultos de la época clásica no tienen un fundamento sólido, porque la oposición existió dede los tiempos más antiguos de la historia romana y fué atenuándose en el transcurso de los siglos, pues esos derechos pertenecieron a categorías totalmente distintas que en época posterior perdieron sus características esenciales y pasaron luego a unificarse bajo la denominación de derechos patrimoniales.

En los tiempos primitivos la antítesis no se presentaba entre derechos reales y derechos de obligaciones en el campo de las relaciones jurídicas patrimoniales, sino que en la rígida estructura de la vida familiar romana se distinguían claramente los derechos que regulaban la vida dentro de la familia romana de los que servían para determinar las relaciones entre las diver. 
sas familias, pues por mucho tiempo el derecho privado de los romanos fué el derecho de los padres de familia.

La familia romana era una institución social totalmente distinta de la organización familiar moderna, debido a que su estructura era fundamentalmente política y gozaba de plena autonomía, que lindaba casi con una completa soberania frente a las agrupaciones políticas mayores, tales como la "gens", la tribu, la ciudad. El jefe era el "pater familias", señor que poseía una extensa potestad sobre la vida y muerte de las personas, libres o esclavos, a él subordinadas, y una absoluta libertad en la disposición de los bie. nes familiares.

Al Estado no se le permitia la menor ingerencia en las relaciones entre diversas familias, las que se regulaban por los vínculos especiales que surgian por el hecho de haberse verificado una ofensa (delito) o por un negocio que se estipulase entre los jefes de las familias (contrato).

De esta organización familiar derivó que los derechos que reglamentaban el interior de las familias tenían características semejantes, las cuales diferian totalmente de las notas esenciales de los derechos que delineaban las relaciones entre diferentes familias.

\section{Características de los derechos en la época quiritaria}

a.-Respecto a la terminología, aparece que la categoría de los derechos en el interior de la familia sobre las personas y sobre las cosas se de. signaban con términos iguales. La potestad sobre personas y bienes se denominaba "manus" y "potestas" indiferentemente; en cambio los derechos que determinan las relaciones entre diferentes familias tienen nombres completamente diversos, como "nexum", "sponsio", etc.

b.-Lo más importante: los mismos remedios procesalęs - "vindicationes"- tutelan los derechos sobre bienes y personas.

Para hacer valer un derecho real se usa una acción real, esto es dirigida a obtener el bien contra cualquier persona que impida el ejercicio de ese derecho. Por eso en el procedimiento "per legis actiones", el titular, por ejemplo del derecho de propiedad, declara: "hunc ego hominem ex iure Quiritium meum esse aie" (yo digo que este hombre es mío según el derecho de los quirites), y en la "intentio" del procedimiento formular se expresa: "si paret hominem de quo agitur ex iure Quiritium Auli Agerii esse" (si parece que el esclavo del cual se trata es de Aulo Agerio según el derecho de los quirites), o sea el titular del derecho de propiedad afirma el dominio objetivo del derecho, esto es un derecho absoluto.

En cambio en los derechos de obligaciones, el demandante en el procedimiento quiritario, exclama: "aio te sestertium decem milia dare oportere" (digo que tú debes dar diez mil sestercios), y en la "intentio" de la fórmula se pone: "si paret Numerium Negidium Aulo Agerio sestertium decem milia dare oportere" (si parece que Numerio Negidio deba dar diez mil sestercios a Aulo Agerio), o sea el titular del derecho de obligación afirma que existe un vinculo entre él $y^{\prime}$ el demandado, esto es un derecho relativo hacia una persona determinada.

c).-Por el objeto también se distinguen evidentemente ambas clases de derechos: el derecho real tiene por objeto una cosa; el derecho de obligación tiene por objeto la actividad de la persona, y la consecuencia es manifiesta en el derecho procesal como se ha indicado. 
d).-Otra característica antitética está en la fuente: los derechos reales tienen fuentes propias; las obligaciones nacen o por un delito o por un contrato.

e).-De ahí que las formas para constituirlos sean diversas: las obligaciones se, constituyen por las formas típicas de la "sponsio" y de la "stipulatio"; los derechos reales, como también los derechos de familia, por la "mancipatio" o la "in iure cessio".

f).-Otra diferencia aparece en que los derechos reales son trasmisibles, mientras que los de obligaciones son intrasmisibles, es decir que estos últimos excluyen las maneras de adquisición derivativa.

g).--Los derechos reales se constituyen virtualmente en perpetuidad, o sea que no pueden ser establecidos a plazo determinado, mientras que las obligaciones son esencialmente temporales.

h).-Finalmente los derechos reales representan verdaderos derechos, mientras los derechos de obligaciones representan relaciones o causas de derechos.

De estas características diferenciales resulta que en el derecho quiritario era evidente la antítesis entre ambas clases de derechos, pues pertenecían ellos a dos esferas completamente distintas: los derechos de obligaciones a las relaciones exteriores entre los "pater familias"; los derechos reales, en unión con los derechos de familia, a las relaciones de soberanía interna de la familia, reservándoseles a cllos la venerable fórmula "ex iure Quiritium".

\section{Atenuación de la antítesis}

En el curso de la evolución del derecho romano esta antitesis se atenúa hasta el extremo que pueden comprenderse ambas clases de derechos en la categoría de los derechos patrimoniales, que se opone a los derechos no patrimoniales. Esto se debió a la disgregación de la familia romana, principalmente por la acción disolvente del Estado sobre los grupos políticos mencres, quitándosele al padre de familia sus facultades soberanas.

a).-El carácter de perpetuidad del derecho real desaparece muy pronto al establecerse figuras de derechos reales como el usufructo y el uso que no son perpetuos, sino que, como los derechos de obligación, están destinados a extinguirse.

b).-Gradualmente se elimina, por necesidades comerciales, la intrasmisibilidad de los cierechos de crédito hasta llegar en el derecho justinianeo a la cesión de créditos, que es un concepto perfectamente paralelo a la enajenación de los derechos reales, convirtiéndose así las obligaciones en algo absolutamente trasmisible y comercial.

En cambio falta el carácter de trasmisibilidad de los derechos reales en los institutos del usufructo y del uso, que se declaran no sujetos a enajenación.

c).-Por lo que se refiere al objeto se debilitan también las opuestas características. Por un lado se admiten tipos de obligaciones que no tienen por olijeto la actividad de una persona, sino el goce de una cosa: por ejemplo la obligación que nace de la locación de cosa. Del otro lado se aceptan tipos cic derechos reales, que no tienen por objeto una cosa, sino la actividad de una persona, por ejemplo la servidumbre "altius non tollendi", tipo de las llamarlas servidumbres negativas, cuyo objeto es la pasividad del propieta. rio del fundo sirviente, o sea no poder elevar la altura de su edificio para no impedir la luz al fundo dominante. 
d).-Respecto a las fuentes también se presentan transformaciones sustanciales. El contrato no sólo constituye exclusivamente, como antes, una obligación sino también un derecho real, y el Emperador Zenón habla del contrato de enfiteusis para indicar el acuerdo que constituye el nuevo derecho real de enfiteusis, y en la recopilación de Justiniano se habla del contrato como fuente de las servidumbres o para la adquisición de la propiedad. Quizá también el mismo delito es reconocido como fuente de adquisición inmediata de la propiedad en favor del sujeto ofendido, por ejemplo el fisco. $Y$ por último la ley, o sea el hecho jurídico puro y simple, independiente del delito o del contrato, se vuelve fuente común de los derechos reales y de las obligaciones.

e).-Paulatinamente desaparece asimismo la diferencia entre las dos categorias respecto a las formas. El acuerdo de voluntades, aunque se pre senta nominalmente con las antiguas formas quiritarias (típico es la perma. nencia de la mancipación aún en documentos del siglo $\mathrm{IX} \mathrm{d}$. $\mathrm{Cr}$.), se convierte en el modo genérico, bajo formas incoloras e indiferentes, de constitución sea de los derechos reales, sea de las obligaciones.

f).-Por último la misma diferencia en la tutela se desvanece en el curso del tiempo. La acción real que protegía los derechos reales, persiguien. do a la cosa, servirá para reivindicar un derecho de crédito; y la acción personal. que tutelaba las obligaciones, defenderá también los derechos reales, hasta que aparecen derechos reales con carácter personal. como las denominadas "Obligaciones reales" $y$ las servidumbres irregulares de la ciencia ro. manista.

Tales atenuaciones de la antítesis primitiva entre los derechos reales y los derechos de obligaciones dieron lugar a que, una vez surgida la noción de patrimonio, se les considerase a ambos bajo la común denominación de los derechos patrimoniales, y que en e1 derecho civil moderno sea difícil encontrar las divergencias precisas entre ambas clases de derechos pues tienen ac tualmente características comunes, agravándose la confusión con la existencia de figuras híbridas, como las mencionadas obligaciones reales y servi. dumbres irregulares que no pueden clasificarse propiamente ni entre los de. rechos reales ni entre las obligacionés puras.

De todo esto resulta que la decantada conquista de la jurisprudencia clásica romana no ha sido tal, sino que en el cutso de la historia del Derecho Romano la originaria antitesis entre los derechos reales y los derechos de obligaciones, que dependia de la organización política de la familia ro. mana, fué desapareciendo hasta llegar a la actual situación, en la que innumerables teorias pretenden justificar esa distinción, sin hallar un sólido fundamento. (Ver: de Ruggiero, Instituciones de Derecho Civil, vol. I, cap. VI \& 22). 